\title{
An Energy Dispersive X-ray Spectroscopy Analysis of Elemental Changes of a Persimmon Phytobezoar Dissolved in Coca-Cola
}

\author{
Masaya Iwamuro ${ }^{1,2}$, Haruo Urata ${ }^{3}$, Reiji Higashi ${ }^{4}$, Masahiro Nakagawa $^{4}$, Shin Ishikawa ${ }^{5}$, \\ Hidenori Shiraha ${ }^{1}$ and Hiroyuki Okada ${ }^{1,6}$
}

\begin{abstract}
To investigate the mechanism of phytobezoar dissolution by Coca-Cola ${ }^{\circledR}$, persimmon phytobezoar pieces removed from a 60 -year-old Japanese woman were analyzed by energy dispersive X-ray spectroscopy. The amount of calcium significantly decreased after dissolution treatment using Coca-Cola ${ }^{\circledR}$, suggesting a potential contribution of calcium to dissolution mechanisms. Moreover, immersion in Coca-Cola ${ }^{\circledR}$ for 120 hours on the exterior surface revealed that Coca-Cola ${ }^{\circledR}$ did not permeate persimmon phytobezoars. This is the first study to investigate the mechanisms of persimmon phytobezoar permeability and dissolution induced by Coca-Cola ${ }^{\circledR}$.
\end{abstract}

Key words: persimmon phytobezoar, diospyrobezoar, cola beverages, dissolution

(Intern Med 55: 2611-2615, 2016)

(DOI: 10.2169/internalmedicine.55.6985)

\section{Introduction}

A bezoar is a rounded mass in the digestive tract comprising a tightly packed collection of semi-digested or undigested material. Since the first report in 2002 by Ladas et al. (1), there have been many case reports and series describing the successful clinical outcome of bezoars treated with Coca-Cola ${ }^{\circledR}$ or other carbonated drinks (2-10). In a report by Ladas et al., 24 articles including 46 patients were reviewed and the authors stated that treatment with CocaCola ${ }^{\circledR}$ led to phytobezoar resolution in $91.3 \%$ of the cases, either as a sole treatment or in combination with an endoscopic procedure (11). We recently investigated the efficiency of in vitro dissolution of phytobezoars by cola beverages. We found that Coca-Cola ${ }^{\circledR}$ and Coca-Cola Zero ${ }^{\circledR}$ showed higher lytic action than the control (water) (12). However, the mechanism of phytobezoar dissolution by cola beverages has never been investigated.
The permeability of cola beverages into persimmon phytobezoars is another uninvestigated issue. A persimmon phytobezoar, i.e., diospyrobezoar, is the most common type of bezoar (13). Unlike other phytobezoars, persimmon phytobezoars are harder and more difficult to fragment or dissolve into small pieces (14). For instance, reports from Korea indicated that $3 \mathrm{~L}$ of cola lavage or drinking resulted in complete dissolution of non-persimmon phytobezoars in $66.7 \%$ (four of six) of cases, while it was not at all effective in patients with persimmon phytobezoars (0 of 11 cases) (8). Our previous case series also showed that persimmon phytobezoars were not dissolved by Coca-Cola ${ }^{\circledR}$ beverages alone and they required endoscopic or surgical removal (6). Such clinical results indicate that persimmon phytobezoars are resistant to cola beverages due to their structural rigidity, which prevents permeation of liquid.

In this paper, we performed two basic studies to reveal the mechanisms of persimmon phytobezoar dissolution by Coca-Cola ${ }^{\circledR}$. First, to investigate the permeation properties,

\footnotetext{
${ }^{1}$ Department of Gastroenterology and Hepatology, Okayama University Graduate School of Medicine, Dentistry, and Pharmaceutical Sciences, Japan, ${ }^{2}$ Department of General Medicine, Okayama University Graduate School of Medicine, Dentistry, and Pharmaceutical Sciences, Japan, ${ }^{3}$ Central Research Laboratory, Okayama University Medical School, Japan, ${ }^{4}$ Department of Internal Medicine, Hiroshima City Hospital, Japan, ${ }^{5}$ Ishikawa Ichouka Clinic, Japan and ${ }^{6}$ Department of Endoscopy, Okayama University Hospital, Japan

Received for publication December 14, 2015; Accepted for publication January 25, 2016

Correspondence to Dr. Masaya Iwamuro, iwamuromasaya@yahoo.co.jp
} 
A

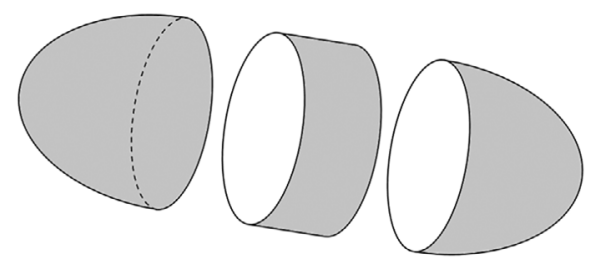

B

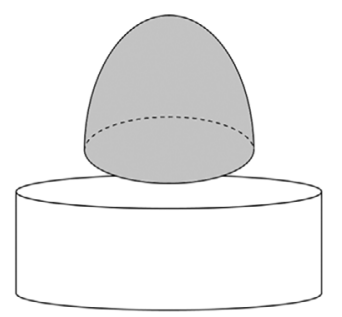

C

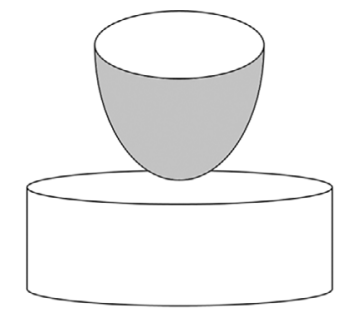

Figure 1. A schematic diagram of the experimental manipulation procedure. The bezoar was cut into three pieces $(A)$. The middle part was used as a control. The remaining pieces were placed on the cut surface side $(B)$ and the exterior surface side (C) in the cell strainers. The bottom $80 \%$ of the pieces was immersed in Coca-Cola ${ }^{\circledR}$ for 120 hours.

dissolubility of persimmon phytobezoar fragments was measured after immersing the cut surface and the exterior surface in Coca-Cola ${ }^{\circledR}$. Second, changes in the elemental composition were investigated by an energy dispersive X-ray spectroscopy analysis of persimmon phytobezoar fragments before and after Coca-Cola ${ }^{\circledR}$ dissolution.

\section{Case Report}

\section{Patient history}

A 60-year-old Japanese woman was diagnosed with a gastric bezoar with an ulcer in the gastric angle by esophagogastroduodenoscopy. The patient had a history of a gastric peptic ulcer, and eradication therapy for Helicobacter pylori was performed at that time. Successful eradication was confirmed by an $H$. pylori antigen stool test. Esophagogastroduodenoscopy also revealed closed-type atrophic gastritis. She drank $1 \mathrm{~L} /$ day of Coca-Cola ${ }^{\circledR}$ for the treatment of the bezoar for 4 days, however, the bezoar was unchanged in size. Although endoscopic fragmentation with a snare device was attempted, it was unsuccessful due to the hard consistency of the bezoar. Finally, a bezoar of $45 \mathrm{~mm}$ in length was endoscopically suctioned and extracted from the stomach en bloc. The spectra obtained from the bezoar showed more than $98 \%$ similarity to those of persimmon extracts $(12,13)$. A medical interview with the patient revealed daily consumption of persimmons for 5 months. Therefore, a diagnosis of a persimmon phytobezoar was made.

\section{Permeability analysis of persimmon phytobezoars}

The bezoar was cut into three pieces and the middle piece was used in an infrared spectroscopy analysis (Fig. 1A, 2A). The persimmon phytobezoar pieces were placed on the cut surface side (Fig. 1B, 2B, left) or the exterior surface side (Fig. 1C, 2B, right) in cell strainers with $40 \mu \mathrm{m}$ pores (Corning Inc., Corning, USA). The cell strainers were set in $50 \mathrm{~mL}$ conical polystyrene tubes and the bottom $80 \%$ of the pieces was immersed in Coca-Cola ${ }^{\circledR}$ (The Coca-Cola Co., Atlanta, USA) for 120 hours at room temperature $\left(25^{\circ} \mathrm{C}\right)$ without stirring. Coca-Cola ${ }^{\circledR}$ was replaced every 24 hours. Subsequently, the persimmon phytobezoar pieces were removed from the cell strainers and photographs of the cell strainers and phytobezoar pieces were taken.

\section{Scanning electron microscopy and energy disper- sive X-ray spectroscopy analyses}

To investigate the elemental composition of the persimmon phytobezoar samples, we used S4800 scanning electron microscopy (Hitachi, Tokyo, Japan) and an EDAX Genesis APEX2 system (Ametek, Paoli, USA). The middle piece of the persimmon phytobezoar pieces that was not used in the immersion experiment was used as a control. The net intensity of each element was measured at three different points on the cut surface of the pieces immersed in Coca-Cola ${ }^{\circledR}$ on the cut surface side (Fig. 1B) for 120 hours and that of the control, respectively. We analyzed the spectrum of the energy dispersive X-ray spectroscopy results using the Genesys software program (Ametek). The amount of each element was quantified using the standardless EDAX ZAF quantification method. For comparisons of the elemental composition, Student's $t$-tests were performed using the JMP 8.0.1 software program (SAS Institute, Cary, USA). A $p$ value less than 0.05 was considered to be statistically significant. Elemental mapping of iron was also performed with S4800 scanning electron microscopy and EDAX Genesis APEX2.

\section{Results}

Photographs of the cell strainers taken after the immersion experiment are shown in Fig. 2C and D. A greater number of dissolved fragments were observed in the cell strainer in which a bezoar piece was placed on the cut surface side (Fig. 2C) than that of the exterior surface side (Fig. 2D). Photographs of the persimmon phytobezoar pieces after the immersion experiment showed that the color of the cut surface was completed changed to black when immersed on the cut surface side (Fig. 2E, left), whereas that of the exterior surface side was only partly changed (Fig. 2E, right). Notably, in the latter piece, color changes were observed along cracks that were incidentally made when cutting the bezoar into pieces, and changes were observed in a limited area close to the surface without cracks.

Scanning electron microscopy showed that there were no obvious changes in the microstructure of the cut surface between samples before (Fig. 3A) and after dissolution by 

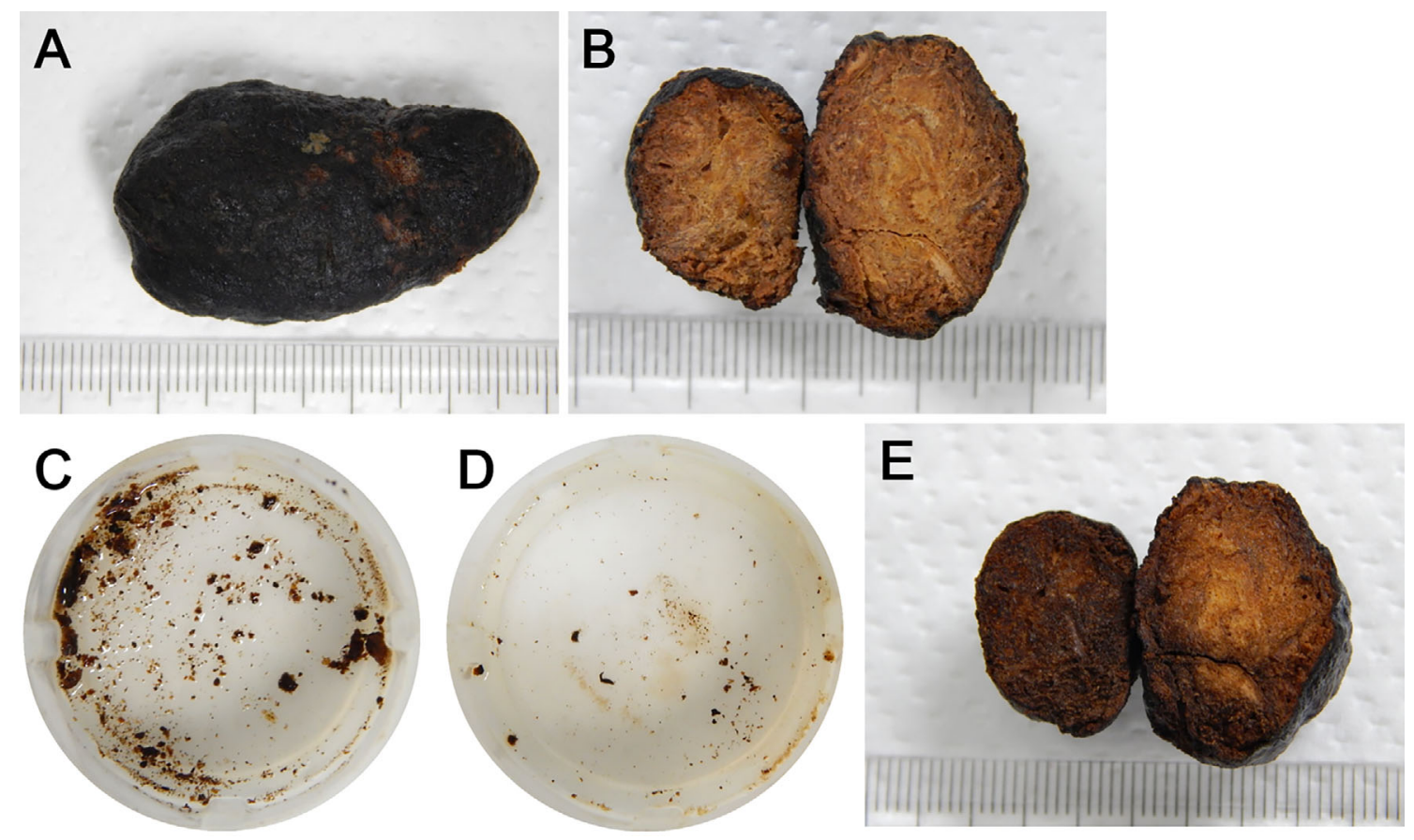

Figure 2. Photographs of the cell strainers and persimmon phytobezoar pieces. The color of the surface is black (A) and that of the inner part is yellow (B), which is consistent with typical persimmon phytobezoars. After the immersion experiment, a greater number of dissolved fragments are observed in the cell strainer in which a bezoar piece was placed on the cut surface side (C), compared with that of the exterior surface side (D). The color of the cut surface entirely changed to black when immersed on the cut surface side ( $E$, left), whereas that of the exterior surface side is only partly changed (E, right).

Coca-Cola ${ }^{\circledR}$ (Fig. 3B). The net intensities of the elements determined by energy-dispersive X-ray spectroscopy of the persimmon phytobezoar pieces are shown in Table. The amount of calcium was significantly reduced and that of sulfur was increased after dissolution treatment by Coca-Cola ${ }^{\circledR}$. The sodium concentration was also decreased, but it was not statistically significant. There were no changes in the amount of carbon, oxygen, or potassium. The samples were likely contaminated with osmium during sample preparation for the electron microscopy analysis because it was used as a fixing agent. A scanning electron microscopy image of the cut surface of the piece before Coca-Cola ${ }^{\circledR}$ treatment (Fig. 3C) and elemental mapping of calcium measured on the same field (Fig. 3D) revealed that calcium was diffusely deposited throughout the phytobezoar piece.

\section{Discussion}

This report is the first study to investigate the permeability of persimmon phytobezoars. Immersion of phytobezoar pieces in Coca-Cola ${ }^{\circledR}$ for 120 hours resulted in a color change to black. The black color was most likely generated by the caramel color contained in Coca-Cola ${ }^{\circledR}$. Therefore, we consider that the area that changed to black color is equal to the area permeated by Coca-Cola ${ }^{\circledR}$. The immersion experiment revealed that $\mathrm{Coca}-\mathrm{Cola}{ }^{\circledR}$ did not permeate the bezoar even after immersion for 120 hours. Our study re- sults are consistent with those previously reported that indicated that Coca-Cola ${ }^{\circledR}$ is ineffective for dissolving persimmon phytobezoars $(6,8,15-17)$. In our previous study, we investigated the ultrastructure of a persimmon bezoar by scanning electron microscopy and found that a high-density layer 20- to $50-\mu \mathrm{m}$ thick constituted the exterior of the phytobezoar (18). Moreover, microgranules formed the exterior surface of the persimmon phytobezoar, which aggregated and created an almost seamless structure with only a few slits. The present study further revealed that infiltration of Coca-Cola ${ }^{\circledR}$ was observed only in a narrow area adjacent to the surface (Fig. 2E). Therefore, according to the microstructural properties revealed by our previous study and the results shown in the present study, we speculate that the almost seamless, dense layers of the exterior surface of the persimmon phytobezoar plays a major role in preventing percolation of liquids.

It was also noteworthy that Coca-Cola ${ }^{\circledR}$ permeated along the cracks, but it did not penetrate into the entire bezoar even after immersion for 120 hours. The inner part of the persimmon phytobezoar comprised sheet-like structures of curved or wiggly shapes, which constituted a honeycomblike appearance (Fig. 2A and B). Although unoccupied areas existed in the inner part, continuous arrangement of the sheet-like structures likely blocks permeation of liquids (18).

Energy-dispersive X-ray spectroscopy revealed that the amount of calcium was significantly reduced after immer- 

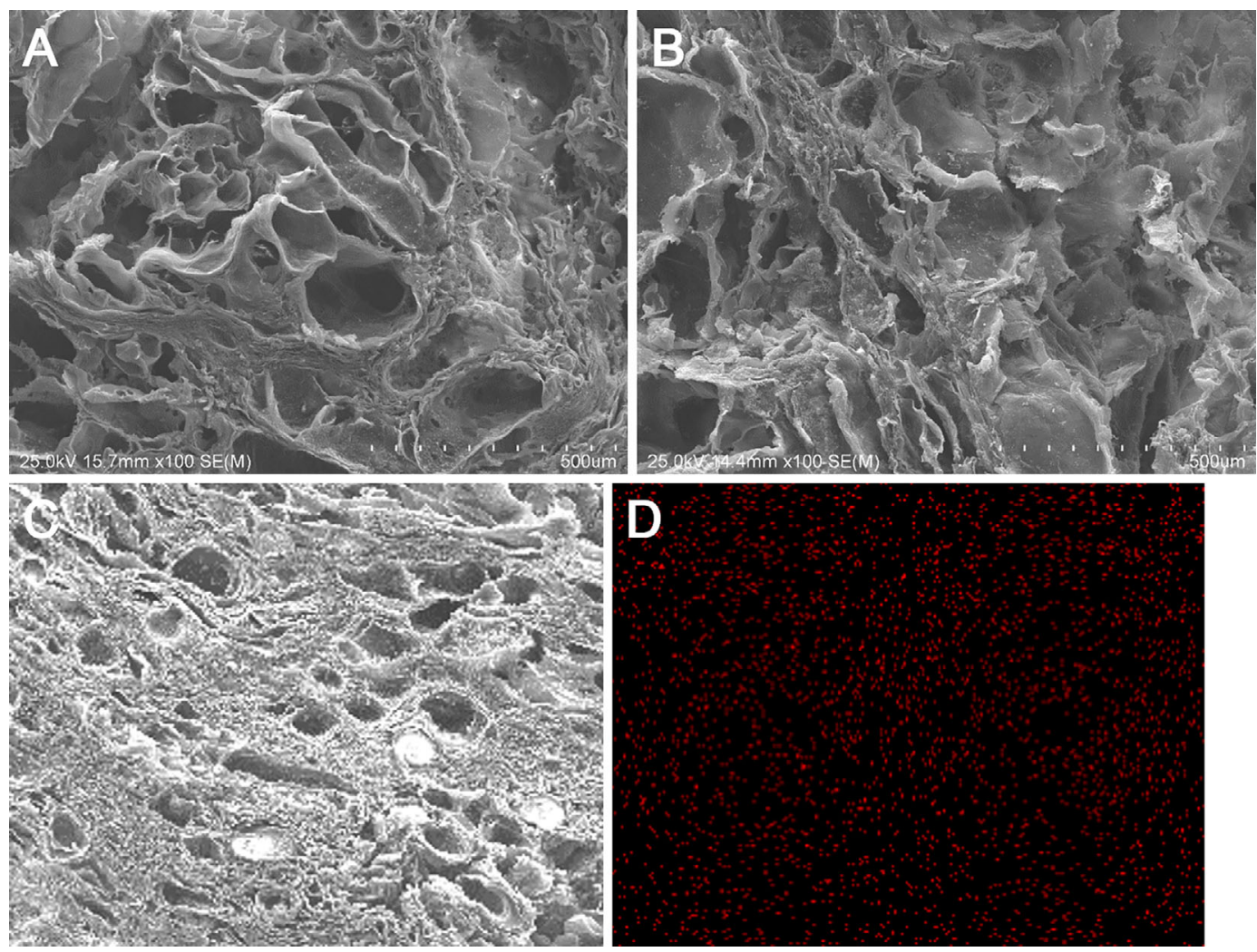

Figure 3. Electron microscopy images. There are no obvious changes in the microstructure of the cut surface between samples before (A) and after dissolution by Coca-Cola ${ }^{\circledR}(\mathrm{B})$. A scanning electron microscopy image of the cut surface of the piece before Coca-Cola ${ }^{\circledR}$ treatment $(C)$ and an elemental mapping image of calcium (D). The calcium element is shown in red and is diffusely deposited in the cut surface.

Table. Net Intensities of Elements Determined by Energy-dispersive X-ray Spectroscopy in a Persimmon Phytobezoar before and after Dissolution by Coca-Cola.

\begin{tabular}{lccc}
\hline & Before & After & p value \\
\hline $\mathrm{C}$ & $127.2 \pm 15.8$ & $131.6 \pm 23.2$ & 0.801 \\
$\mathrm{O}$ & $60.2 \pm 7.0$ & $60.9 \pm 10.8$ & 0.928 \\
$\mathrm{Na}$ & $14.4 \pm 2.2$ & $10.8 \pm 0.9$ & 0.091 \\
$\mathrm{~S}$ & $3.1 \pm 1.0$ & $13.0 \pm 1.6$ & 0.002 \\
$\mathrm{~K}$ & $2.0 \pm 2.4$ & $1.4 \pm 0.3$ & 0.708 \\
$\mathrm{Ca}$ & $4.2 \pm 0.6$ & $1.5 \pm 0.3$ & 0.008 \\
$\mathrm{Os}$ & $8.4 \pm 2.4$ & $6.6 \pm 0.4$ & 0.308 \\
\hline
\end{tabular}

sion in Coca-Cola ${ }^{\circledR}$, suggesting potential mechanisms of phytobezoar dissolution by cola beverages. Carbon dioxide gas and phosphoric acid are widely used in cola drinks and these ingredients impart acidic properties to the products. The acidifying effect of cola beverages may lead to elution of calcium, resulting in bezoar digestion. However, the precise mechanisms of decreased calcium and the role of calcium in the pathogenesis of phytobezoars remain unknown.

An increase in the amount of sulfur was another significant change after immersion in Coca-Cola ${ }^{\circledR}$. Although the formula for Coca-Cola ${ }^{\circledR}$ is not disclosed, carbonated water, high fructose corn syrup, caramel color, phosphoric acid, natural flavors, and caffeine are specified as ingredients on the product label. Certain caramel colors contain sulfurous acid, which may impart sulfur to other objects. However, we solidified Coca-Cola ${ }^{\circledR}$ liquid by air-drying, and the energydispersive X-ray spectroscopy analysis revealed that solidified Coca-Cola ${ }^{\circledR}$ does not contain sulfur (data not shown). Another possibility is that the instruments used in this study contained sulfur, which affected the composition of the bezoar pieces. Nevertheless, because sulfur can be widely found in the human body, plants, and bacteria, the source responsible for changes in the sulfur amount has not been determined thus far.

In summary, this study revealed that Coca-Cola ${ }^{\circledR}$ did not permeate the bezoar even after immersion for 120 hours. Therefore, resolution of persimmon phytobezoars by cola beverages alone is unlikely to be achieved and requires endoscopic or surgical treatment. An analysis of the elemental composition revealed a reduction of calcium after CocaCola ${ }^{\circledR}$ dissolution, indicating a potential contribution of calcium to the dissolution mechanisms.

The authors state that they have no Conflict of Interest (COI).

\section{References}

1. Ladas SD, Triantafyllou K, Tzathas C, Tassios P, Rokkas T, Raptis SA. Gastric phytobezoars may be treated by nasogastric CocaCola lavage. Eur J Gastroenterol Hepatol 14: 801-803, 2002. 
2. Sanders MK. Bezoars: from mystical charms to medical and nutritional management. Pract Gastroenterol 18: 37-50, 2004.

3. Ertuğrul G, Coşkun M, Sevinç M, Ertuğrul F, Toydemir T. Treatment of gastric phytobezoars with Coca-Cola given via oral route: a case report. Int J Gen Med 5: 157-161, 2012.

4. Park SE, Ahn JY, Jung HY, et al. Clinical outcomes associated with treatment modalities for gastrointestinal bezoars. Gut Liver $\mathbf{8}$ : 400-407, 2014.

5. Chung YW, Han DS, Park YK, et al. Huge gastric diospyrobezoars successfully treated by oral intake and endoscopic injection of Coca-Cola. Dig Liver Dis 38: 515-517, 2006.

6. Iwamuro M, Tanaka S, Shiode J, et al. Clinical characteristics and treatment outcomes of nineteen Japanese patients with gastrointestinal bezoars. Intern Med 53: 1099-1105, 2014.

7. Iwamuro M, Yunoki N, Tomoda J, Nakamura K, Okada H, Yamamoto K. Gastric bezoar treatment by endoscopic fragmentation in combination with Pepsi-Cola ${ }^{\circledR}$ administration. Am J Case Rep 16: 445-448, 2015.

8. Lee BJ, Park JJ, Chun HJ, et al. How good is cola for dissolution of gastric phytobezoars? World J Gastroenterol 15: 2265-2269, 2009.

9. Hayashi K, Ohara H, Naitoh I, et al. Persimmon bezoar successfully treated by oral intake of Coca-Cola: a case report. Cases J 1: 385, 2008.

10. Mihai C, Mihai B, Drug V, Cijevschi Prelipcean C. Gastric bezoars: diagnostic and therapeutic challenges. J Gastrointestin Liver Dis 22: 111, 2013.

11. Ladas SD, Kamberoglou D, Karamanolis G, Vlachogiannakos J, Zouboulis-Vafiadis I. Systematic review: Coca-Cola can effectively dissolve gastric phytobezoars as a first-line treatment. Aliment Pharmacol Ther 37: 169-173, 2013.

12. Iwamuro M, Kawai Y, Shiraha H, Takaki A, Okada H, Yamamoto $\mathrm{K}$. In vitro analysis of gastric phytobezoar dissolubility by cocacola, coca-cola zero, cellulase, and papain. J Clin Gastroenterol 48: 190-191, 2014.

13. Iwamuro $\mathrm{M}$, Okada $\mathrm{H}$, Matsueda $\mathrm{K}$, et al. Review of the diagnosis and management of gastrointestinal bezoars. World J Gastrointest Endosc 7: 336-345, 2015.

14. Gayà J, Barranco L, Llompart A, Reyes J, Obrador A. Persimmon bezoars: a successful combined therapy. Gastrointest Endosc 55: 581-583, 2002.

15. Zhang RL, Yang ZL, Fan BG. Huge gastric disopyrobezoar: a case report and review of literatures. World J Gastroenterol 14: 152154, 2008.

16. DeBakey M, Ochsner A. Part 1: Bezoars and concretions. Surgery 4: 934-963, 1938.

17. Lin CS, Tung CF, Peng YC, Chow WK, Chang CS, Hu WH. Successful treatment with a combination of endoscopic injection and irrigation with coca cola for gastric bezoar-induced gastric outlet obstruction. J Chin Med Assoc 71: 49-52, 2008.

18. Iwamuro M, Urata H, Furutani M, et al. Ultrastructural analysis of a gastric persimmon phytobezoar. Clin Res Hepatol Gastroenterol 38: e85-e87, 2014.

The Internal Medicine is an Open Access article distributed under the Creative Commons Attribution-NonCommercial-NoDerivatives 4.0 International License. To view the details of this license, please visit (https://creativecommons.org/licenses/ by-nc-nd/4.0/).

(C) 2016 The Japanese Society of Internal Medicine http://www.naika.or.jp/imonline/index.html 